\title{
Vertical Pit Mining-An Alternative to Open Pit Mining for Massive/Shallow Orebodies
}

\author{
P. J. Terbrugge ${ }^{1}$, R. Armstrong ${ }^{1}$ \\ ${ }^{1}$ SRK Consulting (South Africa)
}

\section{Introduction}

The concept of vertical pit mining has developed as an alternative mining method for the exploitation from surface of small, vertical or near vertical, massive orebodies to depths of approximately $100 \mathrm{~m}$ where ore extraction can become uneconomical due to high stripping ratios. Support of the sidewalls is ensured with systematic anchoring depending on the condition of the insitu rock mass together with the installation of mesh and shotcrete in order to prevent small-scale ravelling and spalling which, with the pit at depth, can prove hazardous to operations at the base of the pit.

Hoisting of the ore is carried out either by a vertical A Frame hoist at the crest of the pit, which requires tramming of ore at the base of the pit to the hoist. Alternatively, a Blondin Cableway system, which allows for loading of kibbles at any location within the pit, negating the need for a tram to the hoist located on the side of the pit, can be utilised.

For various reasons the technique has been successfully applied to the mining of a chrome deposit in Zimbabwe to a depth of $95 \mathrm{~m}$ and a kimberlite pit in West Africa where the pit was terminated at a depth of $85 \mathrm{~m}$ due to a sidewall failure. Feasibility studies for two further vertical pits were conducted for orebodies in South Africa and Australia, kimberlite and nickel respectively, but due to economic considerations, have not been mined.

\section{Performance Requirements}

To receive serious consideration, mining methods must satisfy certain performance requirements with the following points being extremely important: Safety, Technical feasibility, Excavation Stability, Monitoring Capability, Economic Viability, and Acceptable Environmental Impact.

The vertical pits mined to date fundamentally comply with these requirements and possess the advantage that the two main components of the system, lateral support comprising cable anchors and the hoisting systems, are well proven technology and thus provide the required performance with a high level of confidence.

\section{Vertical Pit Design}

The vertical pit design for the kimberlite pipe in West Africa was characterised by a unique set of circumstances comprising political, social, geographical and administrative challenges, with the vertical pit established at the base of an existing pit approximately $50 \mathrm{~m}$ below ground level. Material parameters were obtained from a suite of laboratory tests previously carried out as well as geotechnical mapping of the existing pit walls, including the kimberlite/granodiorite country rock mass. Using the HoekBrown failure criteria the design calculations comprised both 2-dimensional and 3-dimensional numerical analyses to define the cable anchor and rock bolt requirements to provide stability to the excavated vertical wall of the pit. The general support was comprised of the following elements: 
- $20 \mathrm{~m}$ long cable anchors with a $5 \mathrm{~m}$ fixed length tensioned to 40 tons at a $5 \times 7 \mathrm{~m}$ spacing as the primary support,

- $3 \mathrm{~m}$ fully bonded grouted dowels with an ultimate tensile strength of 14 tons at a $2 \mathrm{~m}$ spacing.

- $4 \mathrm{~mm}$ weldmesh with a $150 \mathrm{~mm}$ aperture fixed to the pit wall with "S" pins, covered with $30 \mathrm{MPa}$ shotcrete and a design thickness of $75 \mathrm{~mm}$.

During the mining programme, it became necessary to install $40 \mathrm{~m}$ anchors beneath the headgear to prevent a wedge type failure of the hoist platform. This was achieved with the headgear remaining intact and operational during the life of the vertical pit. The anchor support together with a section through the vertical pit is included as Figure 1.
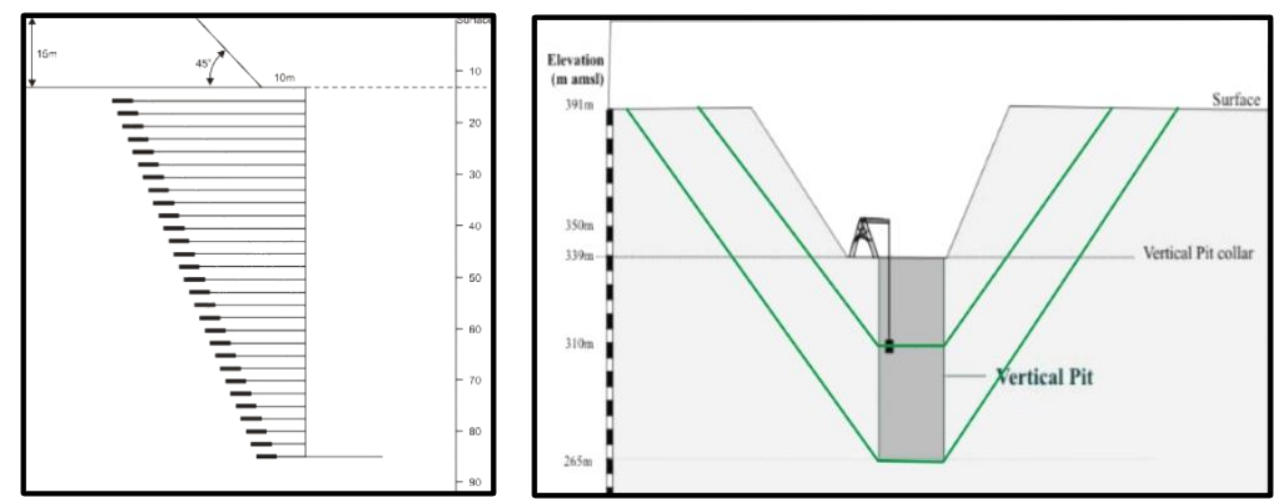

Figure 1: Anchor support with a section through the vertical pit

\section{Implementation}

One of the most important aspects of implementation was the restriction on the time and frequency of blasting due to the number of households within the $250 \mathrm{~m}$ blast envelope, with evacuation of this area required before each blast. With the agreed two blasting cycles per week, coordination of the activities within the pit and adherence to the schedule was of prime importance. The schedule required support installation, including drilling of holes for cable anchors before meshing and shotcrete could be applied, with the cycle having to be completed before the following blast in a particular area of the pit. The cycle time for anchor installation was four days from the time the anchor was installed in the hole, grouted and tensioned. Support and mining production activities therefor have to be carefully synchronised to ensure continuous operations in the pit.

With a limited hoisting capacity and the restricted access at the base of the pit, maintaining ore production targets in order to keep process plants operating at capacity can be a challenge, with downtime necessary for hoist examinations and maintenance on a regular basis. Because of the constricted area at the base of a vertical pit, other factors to be considered, include sump maintenance and drainage in order to maintain a dry operating floor as well as the creation of a free face for optimal blasting results. With the relatively small floor area it is not practically feasible to remove all the mining equipment from the pit bottom for a blast and as such a great deal of emphasis should be put on the blast design. Figure 2 provides a view of the vertical pit and operations at the base of the pit.

In both vertical pits discussed, groundwater played a major role in the design of the operations with vertical wells drilled and pumps installed to lower the groundwater table to acceptable levels. Pore water pressures within the country rock mass were also problematic and where the vertical wells were inadequate, horizontal holes were drilled from within the pit to effect slope drainage.

With the vertical nature of the pit side walls and the potential risk of collapse, slope monitoring played an important part of the slope management programme, with conventional methods being used. 

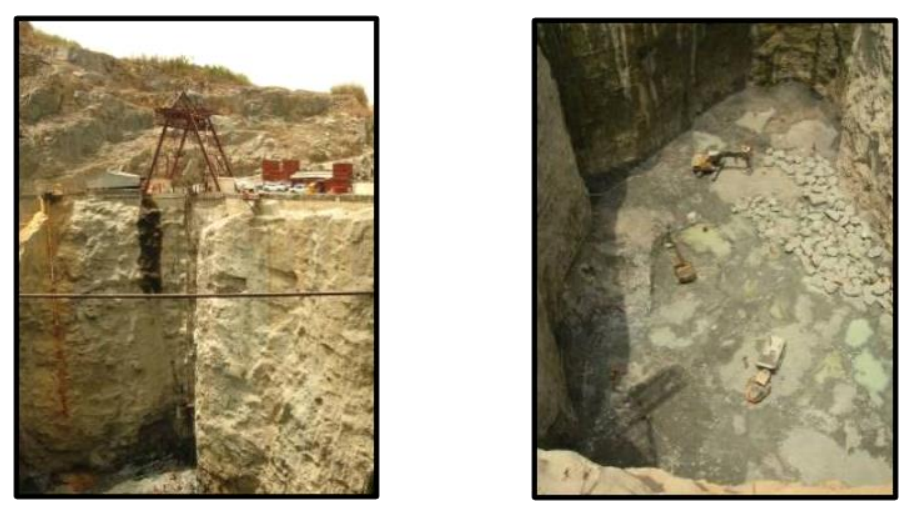

Figure 2: View of the vertical pit with operations at the base of the pit

With respect to the blast design, and a key component being the least damage to the rock mass behind the mine design line, and damage to mining equipment in the confined pit, careful consideration is required in the design. Using the regular open pit "pit limit blast design strategy", blast layouts should comprise pre-splits, a narrow trim and the production blast. The pre-split should be fired first, followed by the production blast and then the trim. Load out arrangements at the base of the pit and surface are shown in Figure 3.
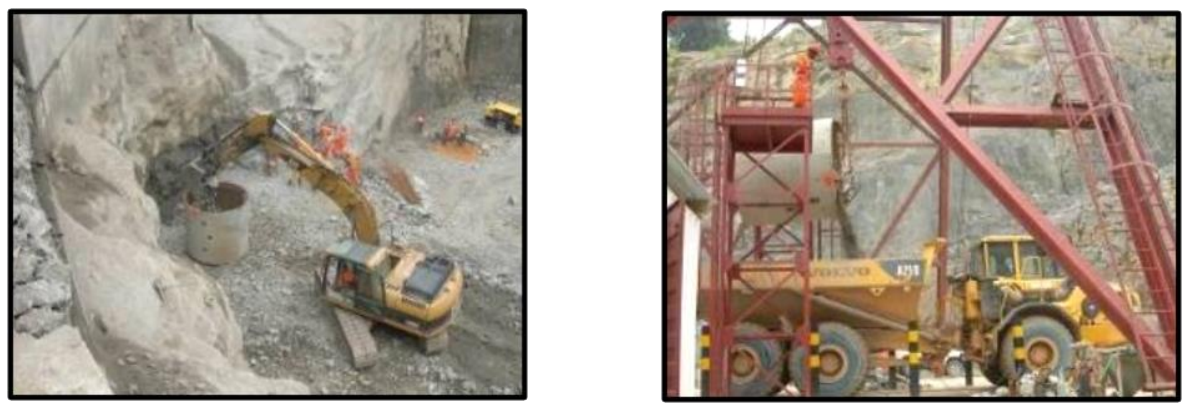

Figure 3: Load out arrangements at the base of the pit and surface

\section{Conclusions}

While vertical pit mining has been shown to be more expensive than conventional open pit mining, the benefit is realised when considering the negligible waste mining required for a return of the same ore tons. The stripping ratio for the West African vertical pit was 0.65 compared to 6.2 on the first cut for a conventional pit and 13.5 on the final cut. Concerning hoisting facilities, a Blondin Cableway System is the preferred option due to its flexibility in that kibbles for loading can be placed at any location within the vertical pit, with ore from the blast muck pile loaded directly into the kibble and hoisted to surface. It is considered that vertical pit mining is a viable alternative to conventional open pit mining and can effectively be exploited on small to medium sized kimberlite pipes.

\section{References}

Redford M S, Terbrugge P J (2000) Vertical Pit Mining - A novel alternative to open pit or underground methods of mining of appropriate massive shallow orebodies. Massmin 2000, Brisbane, Australia.

Joubert J S C, Freeman L A, Terbrugge P J, Venter J (2008) The Koidu Vertical Pit - Sierra Leone. Surface Mining 2008, Southern African Institute of Mining and Metallurgy, Johannesburg, South Africa. 